\title{
La Caja Nacional de Ahorros y la banca estatal: un caso exitoso de economía asociativa entre cajas financieras en Chile, c. 1920-1950
}

\author{
Ignacio González-Correa \\ Universidad de Santiago de Chile
}

Resumen

Este trabajo examina los lazos entre la Caja Nacional de Ahorros y otros bancos estatales como la Caja de Crédito Hipotecario y la Caja de Crédito Agrario entre fines del siglo XIX y la primera mitad del siglo XX. Los permanentes vínculos financieros, la cooperación operativa y el Consejo Directivo compartido entre las 'cajas', explican el éxito y la permanencia en el mercado de las tres firmas estatales. En adición, este trabajo evidencia la relevancia de la Caja Nacional de Ahorros en el mercado del ahorro chileno: en el año 1922 más del 50\% de las personas en Santiago y más del $25 \%$ de la población del país tenía una libreta de ahorro de la 'caja de ahorros', es decir, prácticamente todas las familias del país tenían una cuenta de ahorro en esta institución. La amplia presencia de oficinas de la Caja Nacional de Ahorros en ciudades y localidades donde ningún banco privado tenía sucursales y su sistema de visitas en terreno le permitieron capturar a una gran cantidad de clientes, sobre todo de la clase obrera, la cual estaba dispuesta a ahorrar en el sistema financiero formal. Por último, la trayectoria de estrechas relaciones entre estas empresas es uno de los principales factores que explican por qué estas instituciones fueron fusionadas en 1953 para formar el Banco del Estado de Chile.

Palabras clave:

Cajas de ahorros; bancos estatales; Caja Nacional de Ahorros; Chile

Códigos JEL: G21, N26, G18

\author{
THE CAJA NACIONAL DE AHORROS AND STATE-OWNED BANKS: \\ A SUCCESSFUL CASE OF ASSOCIATIVE ECONOMY AMONG \\ FINANCIAL BANKS IN CHILE, C. 1920-1950
}

Abstract

This work examines the links among the Caja Nacional de Ahorros (National Savings Bank) and other state-owned banks such as the Caja de Crédito Hipotecario (National Mortgage Bank) and the Caja de Crédito Agrario (Agricultural Credit Bank) from the end of the nineteenth-century to the first half of the twentieth-century. The permanent financial links, the operative cooperation, and the shared Board of Directors among the "cajas" explain the success and permanence in the market of the three state-owned firms. In addition, this work shows the relevance of the Caja Nacional de Ahorros in the Chilean savings market: in 1922 more than 50 percent of the people in Santiago and more than 25 percent of the country's population had a savings account of the 'National Savings Bank', that is, practically all the families in the country had a savings account in this institution. The wide presence of offices of the Caja Nacional de Ahorros in cities and towns where no private bank had branches and its system of field visits allowed it to capture many customers, especially the working class, who were willing to save in the formal financial system. Finally, the history of close relationships among these companies is one of the main factors that explain why these institutions were merged in 1953 to form the Banco del Estado de Chile.

Keywords

Savings banks; state-owned banks; Caja Nacional de Ahorros; Chile

JEL codes: G21, N26, G18

Fecha de recepción del original: 4 de abril de 2021; versión definitiva: 12 de mayo de 2021.

Ignacio González-Correa, Investigador asociado. Departamento de Economía, Universidad de Santiago de Chile. Centro de Estudios de Historia Agraria de América Latina (CEHAL). Avenida Libertador Bernardo O'Higgins 3363, Santiago, Chile.

E-mail: ignacio.gonzalez@usach.cl. ORCID ID: http://orcid.org/0000-0003-4842-9685 


\section{La Caja Nacional de Ahorros y la banca estatal: un caso exitoso de economía asociativa entre cajas financieras en Chile, c. 1920-1950}

Ignacio González-Correa

Universidad de Santiago de Chile

1. Introducción

El área financiera y bancaria de la Historia Económica chilena se ha concentrado en la emisión monetaria y los problemas de inflación (Clavel y Jeftanovic 1983; Millar 2005; Briones y Rockoff, 2005; Couyoumdjian 2016), dejando de lado el ámbito institucional, la historia financiera y el campo empresarial. Recientemente, algunos estudios han contribuido a la comprensión del rol de algunas instituciones financieras estatales como la Caja de Crédito Hipotecario (1855-1953) (Brock, 2009) y la Caja de Crédito Agrario (1926-1953) (González-Correa, 2019; González-Correa y RoblesOrtiz, 2022; González-Correa y Llorca-Jaña, 2021). Sin embargo, el ahorro continúa siendo un aspecto sin atender en la disciplina.

En América Latina y, en específico en Chile, no existe abundante literatura sobre las Cajas de Ahorro como sí la hay en España. Una excepción importante son los trabajos sobre las cajas de ahorros en Colombia (Flórez y Solano, 2014) y en Cuba y Puerto Rico (Martínez-Soto, Comín y Roldán de Montaud, 2010), ambos durante el siglo XIX. En la madre patria, las cajas de ahorros han sido objeto de múltiples estudios desde diferentes perspectivas. Por ejemplo, se han investigado las dinámicas competitivas entre la banca comercial y las cajas de ahorros españolas (Maixé-Altés, 2010), el cambio tecnológico de las cajas de ahorros (Bátiz-Lazo y Maixé-Altés, 2011; Maixé-Altés, 2013). En el aspecto administrativo, el modelo colaborativo de las cajas de ahorro españolas en la década de los setenta ha recibido especial atención (Comín, 2008). En adición, en un análisis de largo plazo, Comín (2007) encontró que la trayectoria y el desempeño de las cajas de ahorro españolas eran prácticamente un caso único en Europa y el mundo. En otros casos ilustrativos, las cajas de ahorros fueron analizadas desde una perspectiva regional para explicar su éxito en algunas ciudades y centros agrarios frente a la banca privada (MartínezSoto, 2003; Martínez-Soto y Cuevas-Casaña, 2004) y se estudiaron las funciones financieras y comerciales de las cajas de ahorro y los montes de piedad durante el siglo XIX (Martínez-Soto, 2000). Por su parte, las Cajas de Ahorro de Castilla y León fueron analizadas en el largo plazo por Moreno (2014), mientras que MarbellaSánchez, Martínez-Campillo y Cabeza-García (2008) y MartínezCampillo, Cabeza-García y Marbella-Sánchez (2013) estudiaron la relación entre responsabilidad social y el desempeño empresarial de las cajas entre 2000-2004. Más recientemente, San-José, Retoloza y Pruñonosa (2020) analizaron la transformación de las cajas de ahorros españolas después de la crisis financiera de 2008. En síntesis, tanto sus dinámicas macro -la coordinación entre cajascomo su funcionamiento micro -el caso de Castilla y León y la responsabilidad social- han acaparado la atención de la academia española.

En el caso chileno, la Caja Nacional de Ahorros (1884-1953) ha sido estudiada desde una perspectiva institucional por encargo del Banco del Estado de Chile. La colección de publicaciones del banco comercial estatal está compuesta por Friedmann (1993), Millas (1995) y Cordero (1999, 2000). Las obras de Millas (1995) y Cordero (2000) son investigaciones que tratan exclusivamente la Caja Nacional de Ahorros, mientras que en Friedmann (1993) y en Cordero (1999) las cajas de ahorros se abordan de forma indirecta. No obstante, exceptuando por la obra de Friedmann (1993), estos trabajos tienen un enfoque histórico-descriptivo. En adición, las dinámicas entre las empresas financieras del Estado acaparan algunas menciones aisladas -en algunos casos como anécdotas- sin analizar en profundidad la temática. Por lo tanto, este trabajo se presenta como el primero que estudia las relaciones administrativas, operativas y financieras entre la Caja Nacional de Ahorros, la Caja de Crédito Hipotecario y la Caja de Crédito Agrario. Estos vínculos habrían sido muy importantes, sobre todo desde fines de la década de 1920 hasta 1953, cuando las tres firmas operaron en forma simultánea y coordinada.

La intervención del Estado a través de la creación de instituciones financieras públicas tiene una larga data en el mercado de capitales chileno. En la década de 1880 se creó el primer banco estatal para el ahorro, sin embargo, casi 30 años antes se fundó la Caja de Crédito Hipotecario (1855) con el objetivo de proveer financiamiento utilizando propiedades como garantía (normalmente fundos o haciendas). Posteriormente, durante las primeras décadas del siglo XX, se formarían una serie de bancos o 'cajas' de control del Estado destinados a fomentar distintos sectores de la economía chilena. En efecto, en el año 1926 se creó la Caja de Crédito Agrario con el objetivo de fomentar la agricultura a través del crédito y la venta de insumos para la explotación agrícola (González-Correa y Robles-Ortiz, 2022). Asimismo, a lo largo de la década de 1920, se fundó el Instituto de Crédito Industrial (1928) y la Caja de Crédito Minero (1927), con el objetivo de potenciar a 
través del crédito el sector industrial y minero, respectivamente. En este sentido, Bernedo (1989) muestra cómo estas tres últimas instituciones fueron parte de una política económica exitosa del primer gobierno de Carlos Ibáñez del Campo (1927-1931) para el fomento económico. Por su parte, Ortega (2016) tiene una visión negativa de estas cajas, aunque no realiza un estudio sistemático de estas instituciones sino un análisis general de las políticas de fomento de la primera mitad del siglo XX. No obstante, trabajos más recientes demostraron que la Caja de Crédito Agrario sí tuvo un impacto importante en la agricultura y en el sistema financiero (González-Correa, 2019; González-Correa y Robles-Ortiz, 2022; González-Correa y Llorca-Jaña, 2021).

Durante los años en que las empresas estatales financieras operaron en coordinación (1927-1953), la política económica de Chile experimentó la transición desde el liberalismo económico hacia el intervencionismo estatal, que comenzara incluso antes de la Gran Depresión. La creación del Ministerio de Fomento y de las diferentes cajas de fomento productivo son un reflejo del cambio en la política económica chilena. Además, en la década de 1920, se creó la Caja de Crédito Popular con el objetivo de proveer crédito las clases más pobres a través del empeño de prendas ${ }^{1}$. Sin embargo, la institución que ha recibido mayor atención fue el principal banco estatal durante el proceso de crecimiento económico 'hacia dentro'. La Corporación de Fomento a la Producción (CORFO) fue creada en 1939 con el objetivo de promover el crecimiento económico y la industrialización chilena durante el siglo XX (Ortega et al, 1989; Nazer, Camus y Muñoz, 2009; Nazer, 2016). Su labor fue clave para la creación de otras firmas estatales como la Empresa Nacional de Electricidad (ENDESA) (Nazer y Llorca, 2020), la Compañía de Acero de Pacífico (CAP) y la Empresa Nacional de Petróleos (ENAP), por mencionar algunas. Durante este periodo de gran participación del Estado en materia productiva, las empresas financieras del Estado y, por tanto, la Caja Nacional de Ahorros, fueron parte del aparto estatal que buscó alcanzar la industrialización. No obstante, estas compañías financieras no han recibido la misma atención que otras empresas de los sectores productivos.

Estudiar la Caja Nacional de Ahorros es relevante porque concentraba la mitad del mercado del ahorro Santiago y porque en casi todas las familias chilenas había al menos una libreta de ahorros. El éxito de la compañía fiscal de ahorros radica en su estrategia de capturar ahorro de la clase obrera, las relaciones con otras instituciones fiscales y por su vasta cobertura presencial en un país con una geografía que dificulta el transporte y las comunicaciones. El presente análisis permite obtener una visión desde la región latinoamericana de los bancos de ahorros estatales para comparar el caso chileno con el fenómeno de cajas españolas y casos similares en el mundo. La hipótesis de investigación se concentra en los beneficios, para el éxito operativo y financiero de las tres compañías fiscales, que supuso las actividades coordinadas entre cajas de ahorros, la caja hipotecaria y la caja agraria. La Caja de Crédito Hipotecario actuó como una empresa matricial proveyendo capital a la Caja Nacional de Ahorros y a la Caja de Crédito

\footnotetext{
1 Esta institución, que sería muy demandada por las clases populares, continúa funcionando hasta el día de hoy bajo el nombre coloquial de la 'tía rica' aunque técnicamente se llama ‘Dirección General del Crédito Prendario' dependiente del Ministerio del Trabajo y Previsión social del Gobierno de Chile.
}

Agrario. Además, la caja hipotecaria controlaba directamente las decisiones administrativas de las cajas de ahorro debido a que compartían el Consejo Directivo. Por su parte, la Caja Nacional de Ahorros adquirió acciones de la Caja de Crédito Agrario para que esta última expandiera su capital y funcionó como agente de la caja agraria para ampliar el grado de cobertura del crédito agrícola. Sin embargo, estas relaciones también fueron criticadas principalmente porque la Caja Nacional de Ahorros recogía dinero de la clase obrera y adquiría letras de la caja hipotecaria, mientras esta última empresa se encargaba de dar fondos a grandes propietarios, movilizando capitales desde las clases más bajas hacia las clases más acomodadas.

Este trabajo propone entregar evidencia sobre la relevancia de la Caja Nacional de Ahorros en el mercado de capitales chileno y graficar cómo funcionaban las relaciones entre las tres empresas financieras del Estado. Para lo anterior, se emplearon fuentes propias de las organizaciones como memorias anuales o registros del personal para obtener cifras del número de cuentas y los depósitos de la Caja Nacional de Ahorros. En adición, para la cobertura geográfica se usó el Anuario Estadístico de la República que en su tomo sobre finanzas, bancos y cajas sociales, provee información sobre la distribución de sucursales de la banca comercial y las cajas de ahorros. Asimismo, se utilizaron fuentes primarias y secundarias para recrear el funcionamiento asociativo entre las cajas de ahorro, la caja hipotecaria y la caja agraria.

El artículo se organiza en cuatro secciones: posterior a la introducción, en la parte dos se analiza el origen, la trayectoria y relevancia de mercado de la Caja Nacional de Ahorros, en la sección tres se estudian los vínculos entre la Caja Nacional de Ahorros y otros organismos financieros del Estado, y en el último apartado se entregan las conclusiones.

2. De las cajas de ahorros a la Caja Nacional de Ahorros: origen, expansión y una fusión esperada

El Estado de Chile ha tenido a cargo varias cajas caracterizadas por una importante presencia en el sector financiero chileno, entre éstas las instituciones más grandes fueron Caja de Crédito Hipotecario, la Caja de Crédito Agrario y la Caja Nacional de Ahorros. De hecho, debido a la importancia de estas empresas fiscales en el mercado de capitales, el segundo gobierno de Carlos Ibáñez del Campo (1952-1958) decidió fusionarlas -junto al Instituto de Crédito Industrial- para formar el Banco del Estado de Chile en el año 1953. De estas cuatro empresas, la Caja Nacional de Ahorros era la más relevante por la amplia cobertura geográfica, la gran cantidad de trabajadores, los altos gastos en publicidad y la diversidad de clientes (Friedmann, 1993: 51). Sin embargo, la Caja de Crédito Agrario y la Caja de Crédito Hipotecario también eran relevantes en sus propios mercados: la participación de mercado en el financiamiento de la agricultura de la primera (GonzálezCorrea y Robles-Ortiz, 2022) y, los negocios hipotecarios y la colocación de bonos en el mercado de capitales internacional de la 
segunda (Brock, 2009) ${ }^{2}$. Por su parte, la Caja Nacional de Ahorros, como una institución con decenas de sucursales y gran cantidad de clientes en provincias y en la capital, se formaría recién en 1927 gracias a la unificación de la Caja de Ahorros de Santiago y las distintas cajas de ahorros ubicadas en todo el territorio del país, aunque esta idea sobre ahorro popular tiene antecedentes en la política chilena de la primera mitad del siglo XIX.

Desde comienzos de la vida republicana de Chile, existió entre la clase política y los grandes agricultores la intención de formar un banco para el ahorro de la clase trabajadora. La preocupación por la baja capacidad de ahorro de la sociedad rural chilena fue rápidamente identificada por miembros de la clase política. En el año 1841, la Sociedad Nacional de Agricultura (SNA), agrupación creada en 1838 que congregaba a grandes agricultores de la época, planteó la necesidad de crear 'cajas de ahorros' para los trabajadores chilenos. Al año siguiente, el presidente de la SNA, Pedro Nolasco Mena, fue autorizado por el gobierno para formar una 'Caja de ahorros de Santiago', no obstante, esta empresa no tuvo éxito en sus primeros años de operaciones (Correa Vergara, 1938: 375). Las razones del fracaso de este primer 'banco del ahorro' de carácter privado apuntan a los vicios de la población chilena, como las rifas y loterías, que no contribuían al ahorro. Por lo tanto, se concluyó que era el Estado quien debía intervenir para fomentar el ahorro entre la población chilena (Friedmann, 1993: 52). Finalmente, fue Antonio Varas, un político con experiencia en instituciones financieras públicas, quien lideró la fundación de la Caja de Ahorros de Santiago, la primera institución que posteriormente formaría parte de la Caja Nacional de Ahorros.

La figura del prominente político Antonio Varas fue importante en el desarrollo de la banca durante 1850s-1880s y la creación de la Caja Nacional de Ahorros está basada en su visión para el futuro de la sociedad chilena (Portales, 1890; Correa Vergara, 1938). Antonio Varas fue un destacado estadista que estuvo ligado a la política por más de 40 años ejerciendo en diferentes ámbitos como Ministro de Interior del presidente Manuel Montt (18511861), formador del Partido Nacional o Montt-Varista, y presidente del Senado en la década de 1880. Desde un principio estuvo ligado al mundo financiero como artífice de la creación de la Caja de Crédito Hipotecario (Correa Vergara, 1938) y su sello también se encuentra presente en la ley de Bancos de Emisión del año 1860 (Brock, 2009: 85). Así, en el año 1877 Antonio Varas planteó la idea de crear una Caja de Ahorros en Santiago y presentó sus estatutos en 1879, pero la 'Guerra del Pacífico' o ‘Guerra del Salitre' (1879-1883) detuvo el proyecto (Caja Nacional de Ahorros, 1918). Una vez terminada la guerra, el político volvió a presentar el proyecto declarando que:

"fomentar el ahorro en la clase trabajadora es un medio eficaz de elevar la condición moral de nuestro pueblo, de despertar en ella la previsión que tanta falta y de abrirle camino que le permita esperar que cuando las enfermedades y los años le

\footnotetext{
2 El rol de la Caja de Crédito Hipotecario fue muy relevante para el mercado financiero chileno sobre todo hasta la Gran Depresión. Esta crisis afectó fuertemente a la empresa estatal debido a que tenía una alta exposición al mercado financiero internacional. Sin embargo, a pesar de que a lo largo de casi 100 años la Caja de Crédito Hipotecario tuvo un importante rol en la actividad financiera nacional, la institución ha tenido escasa atención de parte de la literatura especializada que la convirtió en 'el pilar ignorado de las instituciones financieras en Chile' (Brock, 2009: 70).
}

inhabiliten para el trabajo, podrá proveer a las necesidades más imperiosas de la vida, con lo que en tiempo oportuno economizó" (Friedmann, 1993: 55-57).

De esta forma, el 6 de septiembre de 1884 la Caja de Ahorros de Santiago abriría sus puertas a los clientes, tanto para promocionar el ahorro de la clase popular chilena como para mejorar su carácter moral afectado por la 'mala vida'.

La creación de la Caja de Ahorros de Santiago tenía dos objetivos sociales claramente definidos: formular 'economías' o ahorros para las familias chilenas y contribuir a mejorar la condición moral de la clase popular que estaría afectada por el juego y el vicio. El primer propósito era común a otros bancos de ahorros, es decir, canalizar ahorros de sus clientes y pagar intereses sobre los depósitos. Por ejemplo, el Banco Popular (1887) fue un banco cristiano que buscaba promover el ahorro entre las personas más pobres (Santelices, 1893: 400-401), sin declarar la intención de cambiar la moralidad de la sociedad chilena. El aspecto diferenciador entre la Caja de Ahorros de Santiago y otros bancos radicaba en la intención moralista. En este sentido, Guillermo Portales quien fuera contador de la Caja de Ahorros de Santiago en sus primeros años, señaló que:

"el fin con que ella (Caja de Ahorros de Santiago) se propuso por este eminente hombre público (Antonio Varas), fué el de inculcar i fomentar el hábito de economía, por medio del ahorro, en todas las esferas sociales del país i, especialmente, en las clases trabajadoras de nuestro pueblo" (Portales, 1890: 1).

Por su parte, el segundo propósito no era típico para un banco privado. Esta institución debía contribuir a generar ahorros para evitar que las personas gastaran sus ingresos en vicios como el alcohol o juegos de azar. Esta visión de la institución refleja el sentido paternalista del Estado chileno sobre su población. En las palabras del contador,

"[...] la desgracia i triste condición en que se mantienen reducidos (el bajo pueblo), no porque su trabajo les sea poco productivo, que -por el contrario- muchos de ellos ganan más que cierto empleados i profesionales, sino a consecuencia de los hábitos viciosos i depravados en que viven sumergidos; los cuales, además de funestos, son la valla insuperable para lograr que se habitúen a un método de vida ordenado i más conveniente i provechoso para ellos, i que esté más en armonía con la civilización i cultura" (Portales, 1890: 3).

En particular, este segundo propósito estaría ligado directamente al político Antonio Varas, quien fuera identificado como un hombre de principios rígidos y honradez moral, caracterizado por su perseverancia en los estudios y trabajos (Correa Vergara, 1938: 354). En síntesis, la creación de la Caja de Ahorros de Santiago no puede ser entendida como una respuesta meramente económica sino también como una herramienta para formar una 'mejor' sociedad. Estas mismas motivaciones moralistas propiciaron la creación de las cajas de ahorro en Cartagena, Colombia (Flórez y Solano, 2014). En el caso chileno, Guillermo Portales cataloga la labor de la institución como un acto humanitario y patriótico (Portales, 1890: 8). 
La recepción de la población a la nueva institución fue deslumbrante. Esta reacción del público sorprendió a los mismos miembros del Consejo Directivo quienes esperaban que a'nuestro pueblo, con escasa preparación todavía, le sería difícil desprenderse de una parte de sus salarios o sueldos' (Portales, 1890: 13). De hecho, el Consejo Directivo había establecido un mínimo de depósitos de un centavo, dado el comportamiento anterior del público y las malas expectativas de ahorro, y un máximo de 100 pesos al día ${ }^{3}$. Sin embargo, la Caja de Ahorros de Santiago recibió una gran cantidad de clientes desde un principio. Por ejemplo, en los primeros cuatro meses de operaciones se abrieron 861 cuentas por un valor de $\$ 76.224$ pesos (Portales, 1890: 13). En la tabla 1 se muestra el proceso de rápida expansión del negocio de la Caja de Ahorros de Santiago.

Tabla 1. Saldos y cuentas de la Caja de Ahorros de Santiago, 1884-1890*

\begin{tabular}{|c|c|c|}
\hline Año & Depósitos (pesos) & Número de cuentas \\
\hline 1884 & 76.224 & 861 \\
\hline 1885 & 297.724 & 2.480 \\
\hline 1886 & 511.704 & 4.863 \\
\hline 1887 & 911.890 & 7.951 \\
\hline 1888 & 1.260 .255 & 11.830 \\
\hline 1889 & 1.733 .489 & 15.124 \\
\hline 1890 & 1.833 .949 & - \\
\hline
\end{tabular}

Fuente: Portales, 1890: 25

* Las cifras corresponden al 31 de diciembre de cada año, excepto para 1890 donde los saldos corresponden al 30 de junio de 1890 y no hay datos sobre el número de cuentas.

La Caja de Ahorros de Santiago había llegado a captar un público ávido por ahorrar, pero que no encontraba lugar en la banca formal pues esta no recibía ahorros por montos tan pequeños. En el breve periodo de sólo 7 años el número de cuentas creció 17 veces y los saldos en las cuentas de ahorro se multiplicaron por 20. Si se tiene en consideración la población de Santiago en el censo de 1885, las más de 15.000 cuentas de ahorros representan el $5 \%$ de la población de la capital de Chile 4 .

El éxito inicial del banco estatal del ahorro en Santiago favoreció la expansión de la idea hacia las principales ciudades del país. Por medio de fondos estatales y bajo la tutela de Caja de Crédito Hipotecario, en 1901 se abrió una oficina de Caja de Ahorros en Valparaíso, luego, en 1904 se inauguraron las sucursales de lquique y Concepción y, en 1905, continuó la apertura de oficinas en Antofagasta, La Serena, Talca, Chillán, Temuco y Valdivia (Caja Nacional de Ahorros, 1918: 209) ${ }^{5}$. La recepción de la apertura de

\footnotetext{
3 En 1887, debido a la respuesta de los clientes y a las dinámicas operativas, el mínimo fue elevado a 20 centavos.

${ }^{4}$ Estas cifras son mucho más grandes a nivel familiar. Si consideramos un valor conservador de una familia de 4 personas, el 20\% de las familias de Santiago tenía una cuenta de ahorro en la Caja de Ahorros de Santiago.

${ }^{5}$ De hecho, en los siguientes años se abrieron decenas de sucursales a lo largo del país, pero no sólo en las principales ciudades sino también en localidades más pe
}

sucursales en provincias fuera de la capital fue similar a lo experimentado por la Caja de Ahorros de Santiago en sus primeros años. Por ejemplo, la oficina en Concepción en su primer año abrió 171 libretas de ahorros y llegó rápidamente a 14.248 cuentas en 1907 (Friedmann, 1993: 57).

Hacia el centenario de la república se promulgó la ley que permitió la creación de la Caja Nacional de Ahorros. En particular, la ley N⒉356 del 27 de agosto de 1910 declaró la fusión de todas las cajas de ahorros del Estado en una sola institución. La administración superior de esta nueva empresa estatal quedaría a cargo del Consejo de la Caja de Crédito Hipotecario. Sin embargo, esta ley contempló la unificación de todas las cajas de ahorros excepto la más grande de ellas, la Caja de Ahorros de Santiago. Este hecho fue sorpresivo y al poco tiempo surgieron voces que criticaron la medida y que pedían la inclusión de la Caja de Ahorros de Santiago en la Caja Nacional de Ahorros. En 1915 en una conferencia que congregó a decenas de trabajadores y trabajadoras de la institución de ahorro se dieron discursos de sus funcionarios pidiendo la integración no sólo de la Caja de Ahorros de Santiago con la Caja Nacional de Ahorros sino también la integración de esta última con la Caja de Crédito Hipotecario (Caja Nacional de Ahorros, 1918).

La Caja Nacional de Ahorros se posicionó como un banco accesible para la gente, pero, sobre todo, como una institución que se esforzaba por promocionar el ahorro y que generó confianza en las clases populares. La institución declaraba la importancia de no presentar discriminación en su atención a clientes, en años en que sólo un pequeño porcentaje de la población podía acceder al sistema financiero formal. Personas de cualquier edad, sexo ${ }^{6} \mathrm{o}$ condición socioeconómica podían abrir una cuenta de ahorro en la Caja Nacional de Ahorros. En adición, la presencia a través de oficinas en regiones fuera de Santiago y su actividad en terreno fueron dos formas en que las cajas de ahorros se acercaron a la población popular. Por ejemplo, en la zona norte de país ocurrió una dinámica muy cercana entre las familias trabajadoras del salitre y las cajas de ahorros debido a que trabajadores de la empresa financiera constantemente visitaban centros mineros para incentivar el ahorro y abrir cuentas de ahorro para los trabajadores y sus familias. Esta actividad estuvo acompañada de una fuerte publicidad de carácter educativa que buscaba formar el hábito del ahorro entre la clase obrera y los pequeños agricultores. Esta relación creó un vínculo de confianza entre trabajadores y las cajas de ahorros.

La década de 1920 estuvo acompañada de un cambio en la política económica que promovió la creación de instituciones semifiscales para fomentar distintos sectores productivos. En este sentido, el gobierno corporativista de Carlos lbáñez del Campo creó varias cajas y, durante su administración, finalmente se unificaron todas las cajas de ahorros. El 23 de mayo de 1927 se unió la Caja de Ahorros de Santiago a las demás Cajas de Ahorros concretando la demanda de la sociedad y de los mismos trabajadores de las compañías. Con esta definitiva organización, la Caja Nacional de Ahorros consiguió contar con 170 oficinas y cerca de $1 \mathrm{mi}-$ llón 400 mil cuentas de ahorros, en momentos que la población

\footnotetext{
queñas y de difícil conectividad.

${ }^{6}$ En estricto rigor, en la época las mujeres casadas debían contar con el aval de sus maridos.
} 
chilena era cercana a los 4 millones de habitantes (Friedmann, 1993: 55). De esta manera, las cajas de ahorros se convirtieron en importantes miembros de cada ciudad donde estaban ubicadas sus oficinas $y$, por tanto, eran muy sensibles a la realidad regional como sequías, huelgas, ciclos productivos o terremotos. Esto queda ilustrado en la serie de huelgas ocurridas entre 1906 y 1907 en lquique y Antofagasta donde trabajadores de ferrocarriles y la minería exigieron mejores condiciones laborales. Estos eventos afectaron el funcionamiento de las cajas de ahorros. Para ilustrar esto, se puede mencionar que en 1906 la oficina de Antofagasta informaba a través de telegramas a Santiago la creación de una cuenta para recaudar recursos para las familias afectadas por los enfrentamientos entre trabajadores y las fuerzas de orden. En adición, en el año 1907 ocurrió la 'matanza de la Escuela de Santa María', esto es, la muerte de decenas de trabajadores y familiares de la minería del salitre a manos del ejército de Chile, que provocó una gran demanda de retiro de los ahorros de ciudadanos chilenos, peruanos y bolivianos (Friedmann, 1993: 58).

Incluso antes de su fusión, las cajas de ahorros habían logrado consagrar su negocio. Ambas instituciones, la Caja de Ahorros de Santiago y la Caja Nacional de Ahorros, tenían una participación de mercado importante. En el año 1915 la Caja Nacional de Ahorros tenía 415.055 ahorrantes y la Caja de Ahorros de Santiago tenía 171.037 cuentas de ahorros. Esta tendencia se mantendría durante la década de los años veinte (tabla 2).

Tabla 2. Saldos y cuentas de la Caja de Ahorros de Santiago y la Caja Nacional de Ahorros, 1922*

\begin{tabular}{|c|c|c|}
\hline & $\begin{array}{c}\text { Número de } \\
\text { cuentas }\end{array}$ & $\begin{array}{c}\text { Depósitos } \\
\text { (pesos) }\end{array}$ \\
\hline Caja de Ahorros de Santiago & 365.878 & 80.394 .848 \\
\hline Caja Nacional de Ahorros & 667.288 & 180.722 .476 \\
\hline Total & 1.033 .166 & 261.117 .324 \\
\hline
\end{tabular}

Fuente: Caja de Crédito Hipotecario, 1923: 143-171.

* El detalle por oficina de la Caja de Ahorros de Santiago y de la Caja Nacional de Ahorros está en la tabla 4 de la sección Apéndices.

Hacia el año 1922 ambas instituciones dominaban el mercado del ahorro. En particular, si se considera el censo de población de 1920, en la provincia de Santiago vivían 685.358 personas y en todo el país la población ascendía a 3.753.799. La Caja de Ahorros de Santiago tenía más de 365 mil cuentas, esto implica que el 53\% de la población en Santiago tenía una libreta de ahorro en aquella institución. En adición, entre en ambas cajas el total de libretas de ahorro eran más de 1 millón, en decir, el $28 \%$ de la población chilena tenía una cuenta de ahorro (ver tabla 2). En síntesis, en promedio, en todas las familias del país al menos un miembro tenía una cuenta de ahorro asociada a estas cajas estatales ${ }^{7}$.

\footnotetext{
${ }^{7}$ Este cálculo asume que una persona tenía solamente una cuenta de ahorro, lo cual es una conjetura plausible ya que no hay registros de doble cuentas de ahorros sobre una persona en el material revisado en esta investigación. Además, el público principal eran obreros y pequeños agricultores, por tanto, es muy poco probable que este segmento de la población tuviera ingresos suficientes para mantener dos cuentas de ahorro en simultáneo.
}

El destacable desempeño de la Caja Nacional de Ahorros se debe en gran parte a su amplia cobertura geográfica. La concentración de la banca en Valparaíso y Santiago fue una característica propia de Chile desde el siglo XIX y que perduró a lo menos durante gran parte del siglo XX. En este sentido, la presencia de la Caja Nacional de Ahorros en zonas aisladas y sin presencia bancaria fue un factor clave para explicar su buen desempeño. Por supuesto, no se puede omitir la importancia de su política sin restricciones al ahorro y de la seguridad al público que ofrecía por ser una institución estatal. Sin embargo, la presencia geográfica fue abrumante como se muestra en la tabla 3 (apéndices). En el año 1931, la Caja Nacional de Ahorros era la única entidad bancaria con presencia física en más de 50 localidades. En algunos casos su localización es sorprendente debido al alto grado de asilamiento en comunas como Aysén, Puerto Natales o el archipiélago de Chiloé que, por medio del sistema de telegrama, lograban comunicación con la casa matriz en Santiago ${ }^{8}$.

En la década de 1940 algunas voces de la opinión pública comenzaron a evaluar una nueva unión de instituciones financieras fiscales. En aquella oportunidad, se propuso fusionar la Caja Nacional de Ahorros con algunas instituciones de crédito. En efecto, el senador Azócar ${ }^{9}$ presentó una moción para formar la 'Caja Nacional de Ahorros y Créditos' proveniente de la unificación de la Caja Nacional de Ahorros, de la Caja de Crédito Agrario y del Instituto de Crédito Industrial. La respuesta de la prensa fue un rechazo inmediato a la propuesta: el diario más relevante de la época, 'El Mercurio', criticó al senador por sus ideas 'revolucionarias'. En adición, los periódicos ‘La Nación'y 'El imparcial' mostraron sus preocupaciones ante la medida por considerarla 'inconveniente y peligrosa' (Friedmann, 1993: 22-23). Los rumores de una posible fusión de estas entidades fueron creciendo y ya en 1946 se comenzó a hablar entre la prensa, los parlamentarios y los funcionarios de las cajas de una nueva institución llamada'Banco del Estado de Chile.' Al igual que la prensa, los trabajadores y trabajadoras de la Caja Nacional de Ahorros no estaban de acuerdo con la integración con otras cajas del Estado (Friedmann, 1953: 24-25).

Hacia 1950 la Caja Nacional de Ahorros era una empresa madura con una destacada participación de mercado. Por ejemplo, en sus últimos años, casi el 50\% de la población chilena tenía una libreta de ahorro en la institución fiscal de ahorros (Friedmann, 1993: 51). Finalmente, en el año 1953 la segunda administración de Carlos Ibáñez del Campo decidió establecer el 'Banco del Estado de Chile' a través de la unión de la Caja de Crédito Hipotecario (que no estaba en las propuestas de fusión de los años previos), la Caja de Crédito Agrario, el Instituto de Crédito Industrial y la Caja Nacional de Ahorros. Esta última firma fiscal se convirtió en el 'Departamento de Ahorros'y su último presidente, Jorge Prat, se convirtió en el primer presidente del Directorio del Banco del Estado de Chile. No obstante, quizás el legado más tangible para

\footnotetext{
8 Además, la Caja Nacional de Ahorros utilizó otros recursos para expandir sus canales de atención. En efecto, un acuerdo entre el banco privado 'Banco Nacional de Chile' y las cajas de ahorros permitió a la institución fiscal utilizar la red de sucursales de la entidad privada para recibir depósitos a las cuentas de ahorro (Friedmann, 1993: 57).

${ }^{9}$ El senador Guillermo Azócar era un defensor acérrimo de la participación del Estado en la banca y, de hecho, tuvo una participación clave en las discusiones parlamentarias al promover, junto al senador Enrique Zañartu, la creación de la Caja de Crédito Agrario en 1926 (González-Correa, 2019: 7-8).
} 
la sociedad chilena es la presencia del Estado en localidades alejadas o directamente aisladas del sistema financiero formal, la cual mantiene hasta hoy en día ${ }^{10}$ como el único representante presencial de la banca. En efecto, en el año 2019, BancoEstado era el único banco con sucursal en 139 comunas del país las cuales poseen una población de 2 millones de personas (BancoEstado, 2020: 3). En otras palabras, en el $40 \%$ de las comunas del país, BancoEstado es la única entidad bancaria a la que puede acudir presencialmente el $11 \%$ de la población chilena.

3. Las cajas financieras estatales en Chile: un caso de economía asociativa exitoso pero polémico

Desde sus orígenes, las cajas de ahorros estuvieron directamente ligadas a la Caja de Crédito Hipotecario. Antonio Varas, no sólo fue el político artífice de la Caja de Crédito Hipotecario y la Caja de Ahorros de Santiago, como mencionamos anteriormente, sino también fue Director de la empresa hipotecaria desde 1858 hasta su fallecimiento en 1886 (Correa Vergara, 1938: 355356). De esta manera, utilizando su posición de poder dentro de la dirección de la institución y como presidente del Senado, propuso al Consejo Directivo de la firma hipotecaria la idea de fundar la Caja de Ahorros en Santiago (Subercaseaux, 1921: 373; Correa Vergara, 1938: 376). De hecho, el estadista mantendría una posición privilegiada en la toma de decisiones sobre las cajas de ahorros por su participación en el Consejo Directivo.

La Caja de Ahorros de Santiago y posteriormente las demás cajas de ahorros, dependieron directamente del Consejo Directivo de la Caja de Crédito Hipotecario. Este consejo estuvo formado por senadores y diputados, los cuales a lo menos durante el siglo XIX fueron parte de la élite política-agraria chilena. En particular, la Caja de Crédito Hipotecario habría sido un caso de clientelismo político dado que muchos miembros del parlamento -e incluso integrantes del propio Consejo Directivo de la empresa- habrían obtenido créditos de la institución (Bauer, 1975; Bauer, 1994) ${ }^{11}$. El control administrativo inicial de la Caja de Crédito Hipotecario sobre las cajas de ahorros perduró por al menos cuatro décadas más. Durante el siglo XX, por muchos años el presidente de la Caja de Crédito Hipotecario sería otro destacado político nacional, Luis Barros Borgoño ${ }^{12}$. En esta época la Caja de Crédito Hipotecario, la Caja de Ahorros de Santiago y la Caja Nacional de Ahorros fueron administradas por un Consejo Directivo en común liderado por

\footnotetext{
10 Hoy el Banco del Estado de Chile opera bajo el nombre comercial 'BancoEstado'.

11 Bauer destaca que en 1880 sería muy difícil distinguir entre una lista de personas que recibieron fondos de la Caja de Crédito Hipotecario y una nómina del Club de la Unión o del Club Hípico (Bauer, 1994: 116).

12 Luis Barros Borgoño durante fines del siglo XIX y principios del siglo XX fue Ministro de Guerra y Marina, Ministro del Interior, Ministro de Relaciones Exteriores e in cluso vicepresidente de la República en 1925. En el año 1926, mientras ejercía como Director de las tres empresas financieras fiscales, promovió la creación de la Caja de Crédito Agrario (González-Correa, 2019: 8). Además, él invitó a Luis Correa Vergara, influyente agricultor miembro de la Sociedad Nacional de Agricultura, a convertirse en el primer Director-Gerente de la empresa de crédito para la agricultura (Correa Vergara, 1938: 387).
}

Barros Borgoño. Esta relación perduró hasta la promulgación del Decreto con Fuerza de Ley $N^{\circ} 65$ del 30 de marzo de 1931, cuando la Caja Nacional de Ahorros se transformó en una institución con personalidad jurídica propia. No obstante, el aspecto administrativo no fue el único ámbito de relación entre ambas instituciones.

Las finanzas de la Caja Nacional de Ahorros se encontraban supeditadas a la Caja de Crédito Hipotecario. El capital necesario para la apertura de las cajas de ahorros a lo largo de Chile fue provisto por la caja hipotecaria. Por ejemplo, la Caja de Crédito Hipotecario podía utilizar la mitad de los ingresos que generara por intereses penales al fomento y ayuda de las cajas de ahorros (Friedmann, 1993: 82). Sin embargo, las relaciones financieras eran más complejas que la simple provisión de capital.

La empresa fiscal de hipotecas entregaba fondos a largo plazo (más de 10 años) y emitía letras por cada crédito hipotecario que concedía. Estos documentos eran transados en el mercado financiero por dinero y así un prestatario podía obtener entradas a través de la venta de letras extendidas sobre la hipoteca de su propiedad (Bauer, 1994: 114, 136). La Caja de Crédito Hipotecario gozaba de gran reputación por la escasa diferencia entre el valor nominal y el valor de mercado de sus letras. De hecho, las letras emitidas por esta institución estaban en manos de la Caja Nacional de Ahorros y muchos bancos (Bauer, 1994: 115; Brock, 2009: 69). En efecto, estos documentos se convirtieron en un poderoso activo para bancos y para la Caja Nacional de Ahorros (y la Caja de Ahorros de Santiago) debido a la estabilidad del documento patrocinado por la entidad estatal. En consecuencia, la adquisición de letras de la Caja de Crédito Hipotecario se transformó en la típica inversión de bajo riesgo en la banca chilena. No obstante, el vínculo financiero entre la entidad hipotecaria y la Caja Nacional de Ahorros ha provocado fuertes cuestionamientos.

En general, en la Historia Económica de Chile existe la percepción de que la Caja de Crédito Hipotecaria fue una empresa que aparentemente ${ }^{13}$ dirigió el crédito hacia los grandes propietarios de Chile Central (Fetter, 1931; Pinto Santa Cruz, 1959; Bauer, $1975,1994)$. Estos grandes agricultores fueron también parte de élite política de Chile, por lo que la Caja de Crédito Hipotecario se convirtió en una 'herramienta dócil' para mantener su posición privilegiada en la sociedad rural chilena (Bauer, 1994) ${ }^{14}$. En adición, se estableció la noción de que los grandes propietarios que accedieron al crédito de la 'Caja Hipotecaria' habrían sido promotores de la inflación en Chile entre fines del siglo XIX y las primeras décadas del siglo XX (Fetter, 1931). Según esta perspectiva, el crédito hipotecario fue utilizado para mantener una élite

\footnotetext{
13 Los pocos estudios que entregan evidencia empírica sobre la labor de la Caja de Crédito Hipotecario han servido para formular las ideas sobre el rol de la empresa estatal. En particular, Bauer $(1975,1994)$ provee evidencia sobre la concentración del crédito a través del estudio de registros notariales de la provincia de Talca para conclusiones representativas de todo Chile Central. Mientras, Mamalakis (1976) sólo expone antecedentes para la década de 1920 en su crítica a la tesis de culpabilidad de los agricultores en la inflación. Futuras investigaciones con evidencia 'micro' sobre los sujetos de crédito y'macro' sobre las operaciones de la institución, deberán reafirmar o refutar estas hipótesis.

14 Para algunos académicos la creación de la Caja de Crédito Agrario habría sido una medida compensatoria para los grandes agricultores. Según esta visión, la aplicación de la nueva legislatura bancaria que acompañó la 'misión Kemmerer' prohibió el crédito de largo plazo que típicamente daba la Caja de Crédito Hipotecario. Por lo tanto, el gobierno de Carlos Ibáñez del Campo habría decidido formar una nueva institución para compensar a los grandes propietarios agrícolas quienes ya no tenían acceso al conveniente crédito hipotecario (Drake, 1989: 97-98).
} 
política-agraria que estaba altamente endeudada con hipotecas y, por tanto, tenía incentivos para motivar la adopción de una política económica'pro-inflación' (Bauer, 1994: 132). De esta manera, los grandes agricultores que formaban parte de la élite política presionaron para ser beneficiaros de créditos no indexados de la Caja de Crédito Hipotecario en un contexto de inflación creciente para así ajustar la distribución del ingreso a su favor (Bauer, 1975; Mamalakis, 1976). Esta idea fue ampliamente aceptada y tuvo un profundo impacto en la política económica post Gran Depresión (Mamalakis, 1976: 47). Sin embargo, la tesis ha sido criticada debido a que esta misma élite política tomó decisiones contrarias a la dinámica anteriormente expuesta. Por ejemplo, el retorno de Chile al Patrón Oro entre 1895-1898 fue una decisión que no permitió a los grandes propietarios agrícolas beneficiarse de una moneda desvalorizada para financiar las amortizaciones de los créditos hipotecarios (Bauer, 1994: 133). Por su parte, Mamalakis (1976) presentó varios argumentos para explicar por qué esta teoría 'parece estar fundada en la imaginación más que en razones o hechos' (Mamalakis, 1976: 48). En síntesis, la visión negativa de la labor de la Caja de Crédito Hipotecario creó cuestionamientos sobre su intervención en otras firmas estatales como la Caja de Crédito Agrario y la Caja Nacional de Ahorros.

La principal crítica a la cercana relación entre la Caja Nacional de Ahorros y la Caja de Crédito Hipotecario es la transferencia de fondos entre ambas empresas. Mientras la Caja Nacional de Ahorros recogía ahorros desde los obreros y pequeños y medianos agricultores, estos fondos eran traspasados indirectamente a la Caja de Crédito Hipotecario ya que la institución de ahorros adquiría dichas letras hipotecarias. Esto provocó un flujo 'socialmente injusto' desde la clase obrera hacia la clase alta chilena que utilizaba los créditos hipotecarios en vida suntuaria (Bauer, 1994: 115, 135). En particular, la dirección de la Caja de Ahorros de Santiago en un comienzo decidió que el saldo máximo de ahorro era $\$ 1.000$ pesos y, si la persona quería continuar ahorrando estaba obligada a adquirir letras de la Caja de Crédito Hipotecario (Portales, 1890: 14). Sin embargo, esta adquisición representaba un ejercicio de inversión en renta variable ya que el valor de las distintas letras fluctuaba en el mercado por oferta y demanda. Una situación que ilustra esta percepción negativa sobre la caja hipotecaria es la opinión de uno de los principales propulsores de la Caja de Crédito Agrario durante la discusión parlamentaria de la ley que permitió su creación. En aquella ocasión, el senador Guillermo Azócar ${ }^{15}$ indicó que:

'Otro factor particular es el destino de los dineros depositados en la Caja Nacional de Ahorros. El Consejo de la Caja Hipotecaria dedicó el dinero a la edificación, principalmente palacios y chalets para la burocracia y aristocracia. Los 900 millones debían devolver a las Cajas de Ahorros pero no podía realizarse fácilmente por estar invertidos en construcciones en una difícil situación que podría haber llevado a las Cajas de Ahorro a la bancarrota. Para evitar esto, se contrató un empréstito

\footnotetext{
15 Agricultor y Ministro de Agricultura de Carlos Ibáñez del Campo (1931), quien fuera liberal, radical y socialista a lo largo de su vida política. En 1927, logró un movimiento cooperativista, para concentrar la explotación láctea en una sociedad anónima. Fue uno de los primeros en introducir la pasteurización de la leche, en su lechería.
}

con Estados Unidos para recoger los bonos que habían sido lanzados. Ahora se sienten los efectos del empréstito por los intereses que se deben pagar con un capital que se destruyó y que debió invertirse para fomentar la producción.' (Boletín Sesiones Cámara de Senadores, sesión séptima extraordinaria, 16 de marzo de 1926: 203).

De hecho, el rechazo a la Caja de Crédito Hipotecaria como administradora de la Caja de Crédito Agrario fue el único reparo importante que se presentó en toda la discusión parlamentaria. En particular, fueron dos diputados representantes de provincias del sur quienes criticaron a la empresa hipotecaria por la concentración del crédito en Chile Central y el uso de sus fondos para la construcción de grandes edificios para una clase alta privilegiada (González-Correa, 2019; González-Correa y Robles-Ortiz, 2022).

Desde 1926 en adelante, la posición dominante de la Caja de Crédito Hipotecario sobre las cajas de ahorros se extendería hacia la naciente Caja de Crédito Agrario. La institución dedicada al fomento de la agricultura se creó como una filial de la empresa hipotecaria que en un ámbito administrativo dependía de esta última, aunque obedecía a las directrices del Ministerio de Fomento por su rol en la promoción del sector agropecuario. Fue la Caja de Crédito Hipotecario, al igual que con la Caja Nacional de Ahorros, la que entregó los fondos necesarios para la creación de la Caja de Crédito Agrario. Sin embargo, esta dependencia se rompería en 1932 cuando se declaró su autonomía y cambió su dependencia al Ministerio de Agricultura (González-Correa y Robles-Ortiz, 2022).

La Caja Nacional de Ahorros y la Caja de Crédito Agrario también compartieron lazos operativos, pero estos no fueron en forma de control sino de cooperación. En primera instancia, cuando la Caja de Crédito Agrario necesitó más capital para expandir su negocio, la Caja Nacional de Ahorros entregó los fondos necesarios adquiriendo acciones de la primera ${ }^{16}$, pero esto no se tradujo en un control administrativo de la institución de ahorros sino en un mecanismo de expansión de capital por medio de deuda (González-Correa y Robles-Ortiz, 2022) ${ }^{17}$. En segundo lugar, la Caja Nacional de Ahorros funcionó como agente de la Caja de Crédito Agrario para los agricultores en zonas rurales. Durante los primeros años de operaciones, la Caja de Crédito Agrario tenía sólo nueve oficinas y su cobertura geográfica estaba limitada: hasta La Serena por el norte y hasta Osorno por el sur. Por lo tanto, el convenio alcanzado entre ambas instituciones permitió que la empresa dedicada a la agricultura llegara a casi todo el territorio nacional y no estuviera limitada por su número de sucursales. Además, la confianza en la Caja Nacional de Ahorros respaldó las operaciones de la nueva Caja de Crédito Agrario. Este acuerdo habría sido crítico para la expansión del negocio de crédito agrícola (González-Correa y Robles-Ortiz, 2022). Sin embargo, la relación entre ambas empresas no estuvo libre de polémicas. En la década de 1940, la Caja de Crédito Agrario presentó una queja al gobier-

\footnotetext{
16 La Caja Nacional de Ahorros también adquirió acciones del Instituto de Crédito Industrial en su formación en 1928 (Friedmann, 1993: 73). Lamentablemente, no existe mucha información sobre esta última institución en la literatura que permitan profundizar el análisis de sus vínculos.

17 Hacia 1950, al Caja Nacional de Ahorros nuevamente aportó al capital de la Caja de Crédito Agrario. Para conocer el detalle de la capitalización y expansión de sucursales, ver González-Correa y Llorca-Jaña, 2021
} 
Figura 1. Diagrama financiero de la Caja Nacional de Ahorros, la Caja de Crédito Hipotecario y la Caja de Crédito Agrario, circa 1930s-1950s

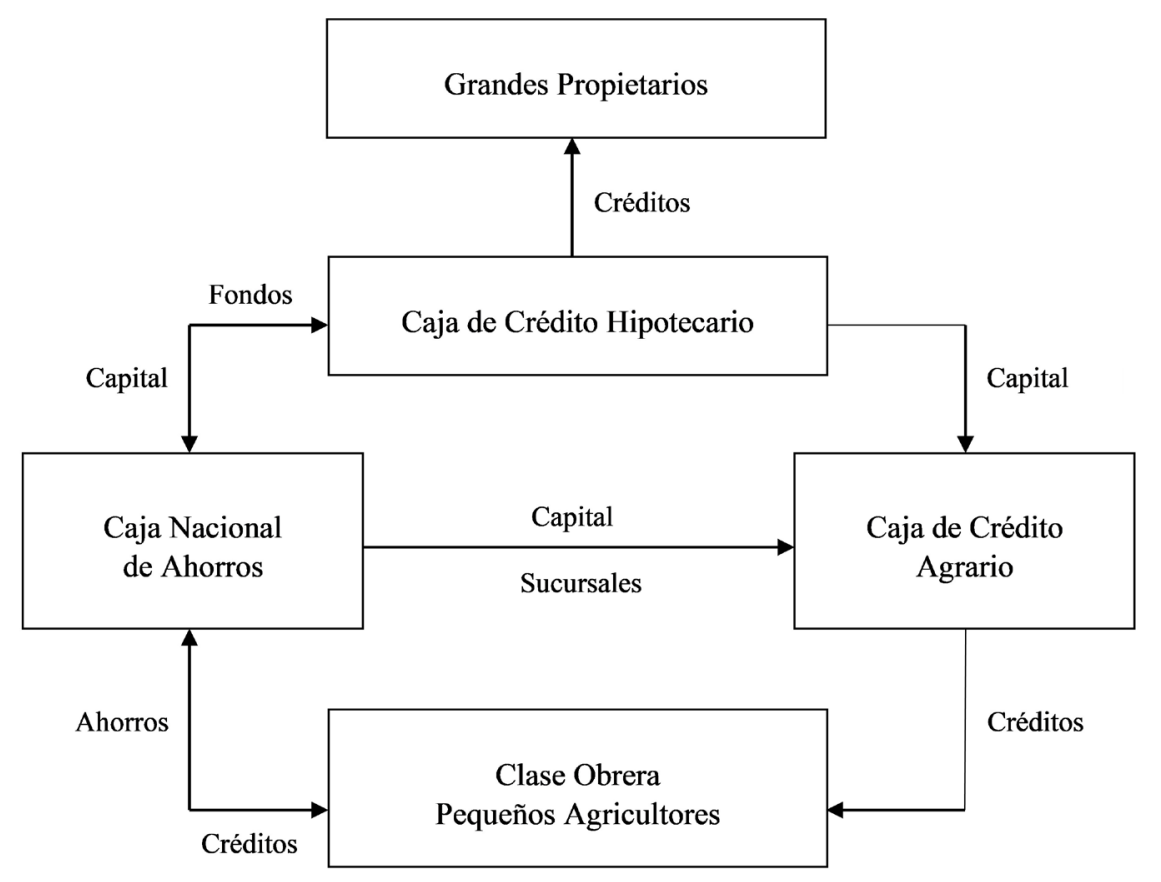

no porque tanto la CORFO como la Caja Nacional de Ahorros entregaban créditos a la agricultura sin tener un mecanismo eficiente para el control del uso del crédito. Lo anterior, provocó que la Caja de Crédito Agrario solicitara que los fondos públicos fueran redireccionados a esta institución en vez de sus pares estatales (Caja de Crédito Agrario, 1944: 6d).

Las dinámicas expuestas nos demuestran las complejas relaciones financieras y de control entre las tres cajas. Los vínculos en ambas direcciones entre la Caja de Crédito Hipotecario, la Caja de Crédito Agrario y la Caja Nacional de Ahorros están sintetizados en la Figura 1. La caja hipotecaria actuaba como la gran empresa matricial de la que dependían las cajas de ahorros y la caja agraria. Mientras la firma hipotecaria proveía el capital para las otras dos empresas, sólo las cajas de ahorros retornaban fondos hacia la empresa ya que la caja agraria se dedicaba exclusivamente a la provisión de créditos y no recibía depósitos del público. Por su parte, el control en el Consejo Directivo era muy marcado sobre la Caja Nacional de Ahorros, pero casi inexistente en la Caja de Crédito Agrario.

Desde el punto de vista de la 'justicia social'ya se ha señalado la transferencia indirecta de ahorros desde la clase baja hacia la esfera social más alta de Chile (sector izquierdo en la Figura 1). Sin embargo, la Caja de Crédito Agrario habría contribuido a 'equilibrar la balanza' dado que su público objetivo fueron los pequeños agricultores a los cuales les ofreció tasa de interés real incluso negativa (González-Correa y Robles-Ortiz, 2022). Una pregunta lógica es si la dinámica operativa y financiera entre las empresas estatales funcionó de forma circular. Es decir, si el dinero ahorrado por la clase obrera y los pequeños agricultores ingresó a través de las cajas de ahorros y luego fue utilizado por la caja hipotecaria para financiar a la caja agraria para dar créditos a la agricultura ${ }^{18}$. La consecuencia de esta mecánica es que los agricultores y obreros se habrían financiado a ellos mismos. La evidencia hasta el momento no apoyaría esta relación: la Caja de Crédito Agrario sólo al principio de sus años de operaciones recibió grandes fondos de la Caja de Crédito Hipotecario, pero fueron notablemente insuficientes ya que incluso con el aporte de capitales de la Caja Nacional de Ahorros la caja agraria tuvo problemas por la escasez de capital. La alta demanda por crédito a la agricultura causó que constantemente esta última empresa tuviera que endeudarse con el Banco Central de Chile para tener los fondos necesarios para operar (González-Correa y Llorca-Jaña, 2021). En efecto, el ente emisor se convertiría en un gran proveedor de fondos para la caja agraria. No obstante, los préstamos no fueron suficientes y en 1945 el fisco proveyó de capital propio a la Caja de Crédito Agrario para su correcto funcionamiento (González-Correa y Llorca-Jaña, 2021; González-Correa y Robles-Ortiz, 2022). En síntesis, el funcionamiento entre las tres compañías no habría sido el de una dinámica circular. De hecho, el comportamiento de este grupo de empresas financieras estatales es similar al funcionamiento del sistema holding. Este modus operandi explica la fusión de estas compañías porque, en la práctica, funcionaban como una gran empresa con áreas especializadas: hipotecas, ahorros y crédito agrícola.

El sentido social de las empresas estatales también determinó las relaciones entre estas compañías generando vínculos no comerciales. La Caja de Crédito Hipotecario tuvo una importante

\footnotetext{
18 La Caja Nacional de Ahorros también entregaba créditos a la agricultura (IBRD$\mathrm{FAO}, 1952)$.
} 
labor en las primeras décadas del siglo XX a través de la construcción y financiamiento de viviendas para la clase obrera, un rol que no ha sido suficientemente destacado por la literatura -a excepción de Cordero (2000)-. En esta actividad, la caja hipotecaria trabajó de forma coordinada con las cajas de ahorro debido a que las propiedades de las poblaciones construidas por la institución en Santiago eran vendidas en mejores condiciones crediticias a los imponentes de la Caja de Ahorros de Santiago. La construcción de poblaciones no estuvo limitada a Santiago y en ciertos casos también favoreció a pequeños campesinos. Algunas de estas poblaciones fueron: la población 'Cochrane' en Valparaíso, la población 'agrícola de Graneros' en Rancagua y la población 'granjas de Lo Ovalle','el Ilano'y'huemul' en Santiago (Caja de Crédito Hipotecario, 1923: 81-96, 101-138).

\section{Conclusiones}

El origen de la Caja Nacional de Ahorros está directamente relacionado a la Caja de Crédito Hipotecario. En la década de 1880 fue la institución hipotecaria la que facilitó el capital para la fundación de la Caja de Ahorros de Santiago. La reacción del público superó las expectativas de la misma caja hipotecaria lo que propició la apertura de nuevas sucursales en Santiago y otras ciudades del país. Hacia 1910 las cajas de ahorros funcionaban exitosamente a lo largo del país y se materializó la fusión esperada de estas instituciones bajo el nombre de la Caja Nacional de Ahorros. No obstante, esta integración dejó fuera a la Caja de Ahorros de Santiago. La opinión pública y los trabajadores de las mismas cajas de ahorros solicitaron la fusión completa, la cual finalmente ocurrió en 1927.

La participación de mercado y su cobertura geográfica demuestran lo relevante que fue la Caja Nacional de Ahorros en el mercado de capitales chileno. En 1922, el 50\% de la población de Santiago tenía una cuenta y se estima que, en promedio, en todas las familias chilenas había al menos una libreta de ahorros de la institución estatal. Las razones del éxito radican en la política de aceptación de depósitos de bajos montos, los lazos financieros, operativos y administrativos con otros organismos del Estado, y la amplia cobertura física de la Caja Nacional de Ahorros. En particular, las cajas de ahorros eran la única presencia bancaria en más de 50 localidades lo cual le permitió acaparar la captación de ahorros en estas comunas. En síntesis, las cifras presentadas en este artículo nos muestran una empresa estatal de ahorros triunfante en el largo plazo. En consecuencia, el éxito las cajas de ahorros españolas ya no sería un caso único en el mundo debido al sobresaliente desempeño de las cajas de ahorros chilenas.

La Caja Nacional de Ahorros se presenta como un caso exitoso, aunque polémico, de economía asociativa en la banca estatal de América Latina. La gran coordinación y el aprovechamiento de beneficios entre las firmas fiscales provocan que la actividad entre la Caja de Crédito Hipotecario, la Caja de Crédito Agrario y la Caja Nacional de Ahorros sea un caso destacable para el sis- tema financiero latinoamericano. Este trabajo expone un primer acercamiento dedicado a las relaciones entre las firmas estatales sobre su funcionamiento cooperativo. En adición, entrega argumentos para comprender por qué estas instituciones fueron elegidas para ser fusionadas y formar el Banco del Estado de Chile. Nuevos análisis de la Caja de Crédito Hipotecario nos permitirán comprobar si sus prestatarios fueron efectivamente la élite-política. En caso de comprobarse, esto reafirmaría la idea de que el dinero de la clase popular almacenado en la Caja Nacional de Ahorros financió indirectamente los gastos lujosos de la alta sociedad chilena. Por último, futuras investigaciones podrán analizar cómo ocurrió el proceso de integración completa entre estas compañías y cómo evolucionaron hacia BancoEstado, el banco estatal comercial del Estado de Chile y uno de los bancos más grandes en Chile. Asimismo, un aspecto relevante que aún no ha sido estudiado es la competencia que ocurrió entre la banca privada del ahorro y la banca estatal del ahorro en Chile.

Agradecimientos

La investigación para este trabajo fue financiada por el proyecto DICYT USACH 2019 “El crédito agrícola y la transición del modelo exportador al 'crecimiento hacia dentro' en Chile, 1900-1938", proyecto USA 1899. Agradezco a Claudio Robles por sus consejos generales y por alentarme a estudiar esta temática. También doy las gracias a Kathya Tapia por ayudarme a organizar mis ideas y por la revisión del texto. Por último, agradezco a Felipe González por su ayuda en la tabulación de algunos datos utilizados en este trabajo.

Bibliografía

BANCOESTADO (2020): Memoria integrada 2019. Al servicio de las personas y empresas. https://www.corporativo.bancoestado.cl/documentos $/ 26$

BÁTIZ-LAZO, B. y MAIXÉ-ALTÉS, J.C. (2011): "Managing Technological Change by Committee: Adoption of Computers in Spanish and British Savings Banks (circa 1960-1988)", Revista de Historia Industrial, 47 (3), pp. 117-150. https://www.raco.cat/index.php/Historialndustrial/article/ view/248227

BAUER, A. J. (1994): La sociedad rural chilena: Desde la conquista española a nuestros días. Santiago, Andrés Bello.

BAUER, A. J. (1975): Chilean Rural Society from the Spanish Conquest to 1930. Cambridge, Cambridge University Press.

BERNEDO, P. (1989): "Prosperidad económica bajo Carlos Ibáñez del Campo, 1927-1929. La dimensión internacional de un Programa Económico de Gobierno", Historia, 24, pp. 5-105. https://repositorio.uc.cl/ handle/11534/9559 
BOLETÍN SESIONES CÁMARA DE SENADORES (1926): Marzo-Julio, 1926. Biblioteca del Congreso Nacional de Chile.

BRIONES, I. y ROCKOFF, H. (2005): "Do Economists Reach a Conclusion on Free-Banking Episodes?", Econ Journal Watch, 2 (2), pp. 279-324. https://econjwatch.org/articles/do-economists-reach-a-conclusionon-free-banking-episodes

BROCK, P. L. (2009): “Secutirización de hipotecas y desarrollo económico: un ensayo sobre la Caja Hipotecaria de Chile", Economía chilena, Banco Central de Chile, 12 (1), pp. 69-93. Disponible en: https://repositoriodigital.bcentral.cl/xmlui/handle/20.500.12580/3514

CAJA DE CRÉDITO AGRARIO (1944): Memoria de la Caja de Crédito Agrario 1943. Santiago, Talleres gráficos "La Nación".

CAJA DE CRÉDITO HIPOTECARIO (1923): La Caja de Crédito Hipotecario y las Cajas de Ahorros de Chile. Santiago, Chile. Librería e imprenta "artes y letras". https://doi.org/10.34720/268x-4e63

CAJA NACIONAL DE AHORROS (1918): Primera Conferencia del Ahorro. Celebrada en Santiago de Chile los días 4, 5, 6, 7, 8 y 9 de diciembre de 1915. Santiago, Sociedad Imprenta-Litografía Barcelona.

CLAVEL, C. y JEFTANOVIC, P. (1983): "Causas de la emisión entre 1878-1919", Revista de Economía. Universidad de Chile, Facultad de Ciencias Económicas y Administrativas. Santiago, 5 (10), pp. 27-34.

COMíN, F. (2007): "Spanish savings banks and the competitive cooperation model (1928- 2002)", Revista de Historia Económica - Journal of Iberian and Latin American Economic History, 25 (2), pp. 201-232. Disponible en: https://doi.org/10.1017/S0212610900000112

COMíN, F. (2008): Historia de la cooperación entre las cajas: la Confederación Española de Cajas de Ahorros (1928-2007). Madrid, Alianza.

CORDERO, R. (1999): Historia de la Caja de Crédito Hipotecario. Banco del Estado de Chile. Santiago, Editorial Don Bosco.

CORDERO, R. (2000): Historia de la Caja Nacional de Ahorros. Santiago:,Banco del Estado de Chile.

CORREA VERGARA, L. (1938): Agricultura Chilena. Tomo I. Santiago, Imprenta Nascimento.

COUYOUMDJIAN, J. P. (ed.) (2016): Economía sin Banco Central. La banca libre en Chile 1860-1898. Santiago, El Mercurio.

DRAKE, P. W. (1989): The Money Doctor in the Andes. The Kemmerer Missions, 1923-1933. Durham and London, Duke University Press.

FETTER, F.W. (1931): Monetary Inflation in Chile. Princeton, Princeton University Press.

FLÓREZ, R. y SOLANO, S. (2014): "Los años de las dificultades: la Caja de Ahorros de la Provincia de Cartagena, Nueva Granada, 1843-1853", América Latina en la Historia Económica, 21 (2), pp. 116-144. https:// doi.org/10.18232/alhe.v21i2.570

FRIEDMANN, L. (1993): Banco del Estado de Chile. Una historia asociada al desarrollo nacional. Santiago, Banco del Estado de Chile.

GONZÁLEZ-CORREA, I. (2019): Fomento estatal a la agricultura post-depresión. La Caja de Crédito Agrario, 1926-1938. Tesis sin publicar. Magíster en Historia Económica, Universidad de Santiago de Chile.

GONZÁLEZ-CORREA, I. y LLORCA-JAÑA, M. (2021): "A state-owned bank for small farmers in Chile, c. 1926-1953", Journal of Evolutionary Studies in Business, 6 (2), pp. 87-125. https://doi.org/10.1344/jesb2021.2.j093.

GONZÁLEZ-CORREA, I. y ROBLES-ORTIZ, C. (2022): “Fostering agriculture under the industrializing state. The Caja de Crédito Agrario and agricultural credit in post-depression Chile, 1926-1953", Historia Agraria, 86 (próximo)

IBRD-FAO (1952): The Agricultural Economy of Chile. Washington, D.C. http://documents.worldbank.org/curated/en/265511468238464167/ The-agricultural-economy-of-Chile

MAIXÉ-ALTÉS, J.C. (2013): "La opción tecnológica de las cajas de ahorro españolas antes de Internet, circa 1950-1995", Investigaciones de Historia Económica, 9 (3), pp. 175-186. https://doi.org/10.1016/j. ine.2012.10.015

MAIXÉ-ALTÉS, J.C. (2010): "Competition and choice: banks and savings banks in Spain", Journal of Management History, 16 (1), pp. 29-43. https://doi.org/10.1108/17511341011008296

MAMALAKIS, M. (1976): The growth and structure of Chilean Economy: from independence to Allende. New Haven and London, Yale University Press.
MARTÍNEZ-CAMPILLO, A., CABEZA-GARCÍA, L. y MARBELLA-SÁNCHEZ, F. (2013): "Responsabilidad social corporativa y resultado financiero: evidencia sobre la doble dirección de la causalidad en el sector de las Cajas de Ahorros", Cuadernos de Economía y Dirección de la Empresa, 16, pp. 54-68. https://doi.org/10.1016/j.cede.2012.04.005

MARBELLA-SÁNCHEZ, F., MARTÍNEZ-CAMPILLO, A. y CABEZA-GARCÍA, L. (2008): “¿Son las cajas de ahorros de Castilla y León socialmente responsables? Influencia de su obra social en el desempleo empresarial", Investigaciones Europeas de Dirección y Economía de la Empresa, 14 (2), pp. 71-86. https://doi.org/10.1016/S1135-2523(12)60024-0

MARTíNEZ-SOTO, A. P., COMÍN, F. y ROLDÁN DE MONTAUD, I. (2010): Las cajas de ahorros de las provincias de ultramar, 1840-1898. Cuba y Puerto Rico. Madrid, Fundación de Las Cajas de Ahorros (FUNCAS).

MARTÍNEZ-SOTO, Á. P. (2000): "Las cajas de ahorro españolas en el siglo xix: entre la beneficencia y la integración en el sistema financiero", Revista de Historia Económica - Journal of Iberian and Latin American Economic History, 18 (3), pp. 585-628. https://doi.org/10.1017/ S0212610900008740

MARTÍNEZ-SOTO, Á. P. (2003): "El papel de las cajas de ahorro en la captación del pequeño ahorro desde una perspectiva regional", Papeles de Economía Española, 97, pp. 174-203.

MARTÍNEZ-SOTO, Á. P. y CUEVAS-CASAÑA, J. (2004): “La expansión y consolidación de las cajas de ahorro en el sistema financiero español", Revista de Historia Económica - Journal of Iberian and Latin American Economic History, 22 (1), pp. 65-110. https://doi.org/10.1017/ S0212610900010879

MILLAR, R. (2005): Políticas y Teorías Monetarias en Chile, 1810-1925. Santiago, Gabriela Mistral.

MILLAS, H. (1995): Historia de Centavos. Banco del Estado de Chile. Santiago, Editorial Don Bosco.

MORENO, J. (2014): "Empresariado, Iglesia y ahorro popular: las cajas de ahorro y Montes de Piedad de Castilla y León, 1841-2013", Investigaciones de Historia Económica, 10, 3, pp. 177-190. https://doi. org/10.1016/j.ihe.2013.08.001

NAZER, R., CAMUS, P. y MUÑOZ, I. (2009): Historia de la Corporación de Fomento de la Producción, CORFO. http://repositoriodigital.corfo.cl/

NAZER, R. (2016): "La Corporación de Fomento a la Producción y la modernización económica de Chile. 1939-1970", Revista de Gestión Pública, 5 (2), pp. 283-316. http://www.revistadegestionpublica.cl/index.php/ rgp/article/view/75

NAZER, R. y LLORCA-JAÑA, M. (2020): "Chile's National Electricity Company (ENDESA): a successful case of state-led national electrification, c.1936-1981", Revista de Historia Industrial, 80, pp. 183-222.

ORTEGA, L., NORAMBUENA, C. PINTO, J. y BRAVO, G. (1989): Corporación de Fomento de la Producción: 50 años de Realizaciones 1939-1989. Santiago, Universidad de Santiago de Chile.

ORTEGA, L. (2016): "Políticas de "fomento" en una sociedad en transición: Desafíos y obstáculos. Chile en la primera mitad del siglo XX", Atenea 514, pp. 13-29. https://revistasacademicas.udec.cl/index.php/atenea/ article/view/42

PORTALES, G. (1980): La economía individual i la Caja de Ahorros de Santiago. Sobre las operaciones que este establecimiento ha tenido desde su fundación hasta el presente. Santiago, Imprenta Santiago.

PINTO SANTA CRUZ, A. (1959): Chile, un caso de desarrollo frustrado. Santiago, Editorial Universitaria

SAN-JOSÉ, L., RETOLOZA, J. L. y PRUÑONOSA, J. T. (2020): “Eficiencia social en las cajas de ahorro españolas transformadas en bancos", El trimestre económico, 347 (3), pp. 759-787. https://doi.org/10.20430/ete. v87i347.882

SANTELICES, R. (1893): Los bancos chilenos. Santiago, Imprenta y encuadernación Barcelona.

SUBERCASEAUX, G. (1921): El sistema monetario i la organización bancaria en Chile. Santiago, Imprenta Universo. 
Apéndices

Tabla 3. Cobertura geográfica de la Caja Nacional de Ahorros, 1931

\begin{tabular}{|c|c|c|c|c|c|}
\hline Localidad & $\begin{array}{l}\text { Su- } \\
\text { cur- } \\
\text { sales }\end{array}$ & $\begin{array}{c}\text { A- } \\
\text { gen- } \\
\text { cias }\end{array}$ & Localidad & $\begin{array}{l}\text { Su- } \\
\text { cur- } \\
\text { sales }\end{array}$ & $\begin{array}{c}\text { A- } \\
\text { gen- } \\
\text { cias }\end{array}$ \\
\hline Arica & 1 & & Curicó & 1 & \\
\hline Iquique & 1 & & Curepto* & & 1 \\
\hline Tocopilla & 1 & 2 & Molina* & 1 & \\
\hline Calama* & 1 & 1 & Talca & 1 & \\
\hline Antofagasta & 1 & 1 & San Javier* & 1 & \\
\hline Mejillones* & & 1 & Linares & 1 & \\
\hline Taltal* & 1 & & Parral & 1 & \\
\hline Chañaral* & 1 & & Constitución & 1 & \\
\hline Potrerillos* & 1 & & Cauquenes & 1 & \\
\hline Copiapó & 1 & & San Carlos & 1 & \\
\hline Vallenar & 1 & & Chillán & 1 & \\
\hline La Serena & 1 & & Yungay* & 1 & \\
\hline Coquimbo & 1 & & Bulnes* & 1 & \\
\hline Vicuña* & 1 & & Coelemu* & 1 & \\
\hline Ovalle & 1 & & Quirihue* & 1 & \\
\hline Illapel* & 1 & & Tomé* & 1 & \\
\hline Salamanca* & & 1 & Concepción & 1 & \\
\hline La Ligua* & 1 & & Talcahuano & 1 & \\
\hline Cabildo & & 1 & Yumbel* & 1 & \\
\hline Petorca* & & 1 & Cabrero* & 1 & \\
\hline San Felipe* & 1 & & Coronel* & 1 & \\
\hline Putaendo* & 1 & & Lota* & 1 & \\
\hline Los Andes & 1 & & Arauco* & 1 & \\
\hline La Calera & 1 & & Lebu* & 1 & \\
\hline Llay-Ilay* & 1 & & Los Ángeles & 1 & \\
\hline Quillota & 1 & & Laja* & & 1 \\
\hline Valparaíso & 2 & & Mulchén & & 1 \\
\hline Viña del mar & 1 & & Nacimiento* & & 1 \\
\hline San Fco. de Limache* & 1 & & Angol & 1 & \\
\hline Quilpué* & & 1 & Collipulli & 1 & \\
\hline Casablanca* & 1 & & Traiguén & 1 & \\
\hline Santiago & $10 * *$ & & Victoria & 1 & \\
\hline Puente Alto* & 1 & & Curacautín* & 1 & \\
\hline Talagante* & 1 & & Lautaro & 1 & \\
\hline San Antonio* & 1 & & Temuco & 1 & \\
\hline Melipilla* & 1 & & Freire* & & 1 \\
\hline San Bernardo* & 1 & & Nueva Imperial* & 1 & \\
\hline Buin* & 1 & & Pitrufquén* & 1 & \\
\hline Rancagua & 1 & 4 & Loncoche* & 1 & \\
\hline Graneros* & 1 & & Valdivia & 1 & \\
\hline Peumo* & & 1 & La Unión & 1 & \\
\hline Rengo & 1 & & Osorno & 1 & \\
\hline
\end{tabular}

\begin{tabular}{|l|c|c|l|r|l|}
\hline Requínoa* & & 1 & Puerto Montt & 1 & \\
\hline $\begin{array}{l}\text { S. Vicente de T. Ta- } \\
\text { gua* }\end{array}$ & 1 & & Ancud* & 1 & \\
\hline San Fernando & 1 & & Castro* & 1 & \\
\hline Nancagua* & & 1 & Aysén* & 1 & \\
\hline Chimbarongo* & 1 & & Magallanes & 1 & \\
\hline Santa cruz & 1 & & Puerto Natales* & 1 & \\
\hline & & & Total & 92 & 21 \\
\hline
\end{tabular}

Fuente: Dirección General de Estadística. Chile (1932). Anuario Estadístico de la República de Chile. Estadística anual de la Finanzas, bancos y cajas sociales. Año 1931. Tomo: Finanzas, bancos y cajas sociales: 30.

* Localidad donde la Caja Nacional de Ahorros era la única presencia bancaria.

** Incluye la oficina matriz.

Tabla 4. Distribución de cuentas y depósitos por oficina, Caja de Ahorros de Santiago y Caja Nacional de Ahorros, 1922

\begin{tabular}{|c|c|c|}
\hline Oficina & Cuentas & $\begin{array}{c}\text { Depósitos } \\
\text { (pesos) }\end{array}$ \\
\hline \multicolumn{3}{|c|}{ Caja de Ahorros de Santiago } \\
\hline Oficina Central & 151.186 & 41.805 .044 \\
\hline Estación & 53.668 & 9.332 .894 \\
\hline Providencia & 21.360 & 4.225 .574 \\
\hline Independencia & 20.872 & 2.764 .033 \\
\hline Bella-Vista & 10.402 & 2.093 .047 \\
\hline Huemul & 14.023 & 2.125 .871 \\
\hline San Pablo & 10.916 & 1.668 .575 \\
\hline San Diego & 13.793 & 2.565 .389 \\
\hline Yungay & 15.974 & 2.939 .428 \\
\hline Melipilla & 5.753 & 1.206 .382 \\
\hline San Bernardo & 6682 & 2.036 .675 \\
\hline Graneros & 1.518 & 315.239 \\
\hline San Antonio & 3.616 & 563.782 \\
\hline Puente Alto & 2.844 & 822.642 \\
\hline Ñuñoa & 3.367 & 915.084 \\
\hline Talagante & 2.835 & 545.581 \\
\hline Población Huemul & 6.249 & 267.243 \\
\hline Manuel Montt & 4.183 & 934.746 \\
\hline Matadero & 3.981 & 1.288 .423 \\
\hline Avenida Matta & 7.944 & 1.273 .791 \\
\hline Parque & 4.712 & 705.405 \\
\hline Total Caja de Ahorros de Santiago & 365.878 & 80.394 .848 \\
\hline
\end{tabular}




\begin{tabular}{|c|c|c|}
\hline \multicolumn{3}{|c|}{ Caja Nacional de Ahorros } \\
\hline Tacna & - & 2.686 .565 \\
\hline Arica & 5.160 & 1.607 .530 \\
\hline Iquique & 51.290 & 7.163 .590 \\
\hline Antofagasta & 48.146 & 8.638 .660 \\
\hline Tocopilla & 5.529 & 1.616 .959 \\
\hline Taltal & 9.731 & 1.474 .828 \\
\hline Chuquicamata & 5.098 & 1.018 .673 \\
\hline Copiapó & 7.450 & 1.488 .214 \\
\hline Caldera & 1.329 & 371.564 \\
\hline Vallenar & 4.942 & 640.922 \\
\hline Chañaral & 2.315 & 407.783 \\
\hline Potrerillos & 970 & 262.920 \\
\hline Serena & 29.262 & 5.238 .311 \\
\hline Ovalle & 7.362 & 1.518 .338 \\
\hline Coquimbo & 6.358 & 2.014.847 \\
\hline San Felipe & 10.530 & 1.823 .287 \\
\hline Los Andes & 6.291 & 1.472 .182 \\
\hline Putaendo & 1.708 & 370.060 \\
\hline Llay-Llay & 2.666 & 812.546 \\
\hline Principal de Valparaíso & 16.124 & 17.192 .620 \\
\hline Puerto, (Valparaíso) & 15.179 & 3.231 .768 \\
\hline Prat, (Valparaíso) & 11.154 & 28.471 .734 \\
\hline Almendral, (Valparaíso) & 18.043 & 4.481 .364 \\
\hline Viña del Mar & 15.319 & 3.321 .069 \\
\hline San Francisco de Limache & 4.233 & 1.641 .678 \\
\hline Quillota & 9.295 & 3.168 .402 \\
\hline Calera & 5.998 & 1.572 .675 \\
\hline Rancagua & 15.188 & 2.855 .414 \\
\hline Buin & 3.979 & 1.048 .980 \\
\hline San Fernando & 8.824 & 2.304 .786 \\
\hline Rengo & 4.296 & 1.090 .788 \\
\hline San Vicente de Tagua Tagua & 1.950 & 1.132 .422 \\
\hline Chimbarongo & 1.709 & 338.350 \\
\hline Curicó & 18.358 & 2.336 .430 \\
\hline Teno & 993 & 435.925 \\
\hline Santa Cruz & 1.808 & 669.818 \\
\hline Talca & 28.886 & 4.420 .348 \\
\hline Molina & 2.822 & 426.094 \\
\hline Constitución & 5.919 & 1.830 .208 \\
\hline Linares & 8.327 & 2.059 .061 \\
\hline San Javier & 3.864 & 779.911 \\
\hline Parral & 4.935 & 966.656 \\
\hline Cauquenes & 12.131 & 1.685 .853 \\
\hline Quirihue & 2.865 & 593.407 \\
\hline Chillán & 31.146 & 8.513 .394 \\
\hline
\end{tabular}

\begin{tabular}{|c|c|c|}
\hline San Carlos & 3.916 & 1.248 .001 \\
\hline Bulnes & 2.911 & 714.620 \\
\hline Yungay & 1.499 & 356.769 \\
\hline Coelemu & 722 & 516.482 \\
\hline Cabrero & 602 & 404.850 \\
\hline Concepción & 55.662 & 8.422 .431 \\
\hline Yumbel & 1.904 & 808.935 \\
\hline Talcahuano & 16.677 & 2.430 .746 \\
\hline Tomé & 3.129 & 763.571 \\
\hline Coronel & 2.747 & 934.061 \\
\hline Lota & 3.058 & 1.206 .630 \\
\hline Lebu & 3.396 & 549.348 \\
\hline Curanilahue & 2.397 & 562.318 \\
\hline Cañete & 878 & 253.089 \\
\hline Arauco & 1.218 & 560.383 \\
\hline Los Ángeles & 9.804 & 2.807 .088 \\
\hline Nacimiento & 1.140 & 342.330 \\
\hline Mulchén & 1.282 & 352.473 \\
\hline Angol & 4.615 & 773.437 \\
\hline Traiguén & 4.079 & 449.209 \\
\hline Temuco & 22.418 & 3.614 .631 \\
\hline Collipulli & 1.718 & 372.289 \\
\hline Victoria & 4.016 & 1.023 .329 \\
\hline Lautaro & 4.320 & 597.895 \\
\hline Pitrufquén & 2.181 & 509.098 \\
\hline Freire & 1.090 & 378.140 \\
\hline Curacautín & 1.093 & 345.920 \\
\hline Valdivia & 32.000 & 4.028 .053 \\
\hline Puerto Montt & 5.360 & 1.411 .458 \\
\hline Osorno & 4.279 & 991.106 \\
\hline Puerto Varas & 2.427 & 230.797 \\
\hline Ancud & 3.277 & 1.200 .771 \\
\hline Castro & 1.961 & 627.155 \\
\hline Santiago (Tesorería) & 30 & 3.738 .129 \\
\hline Total Caja Nacional de Ahorros & 667.288 & 180.722 .476 \\
\hline Total ambas instituciones & 1.033 .166 & 261.117.324 \\
\hline
\end{tabular}

Fuente: Caja de Crédito Hipotecario, 1923: 143-171. 


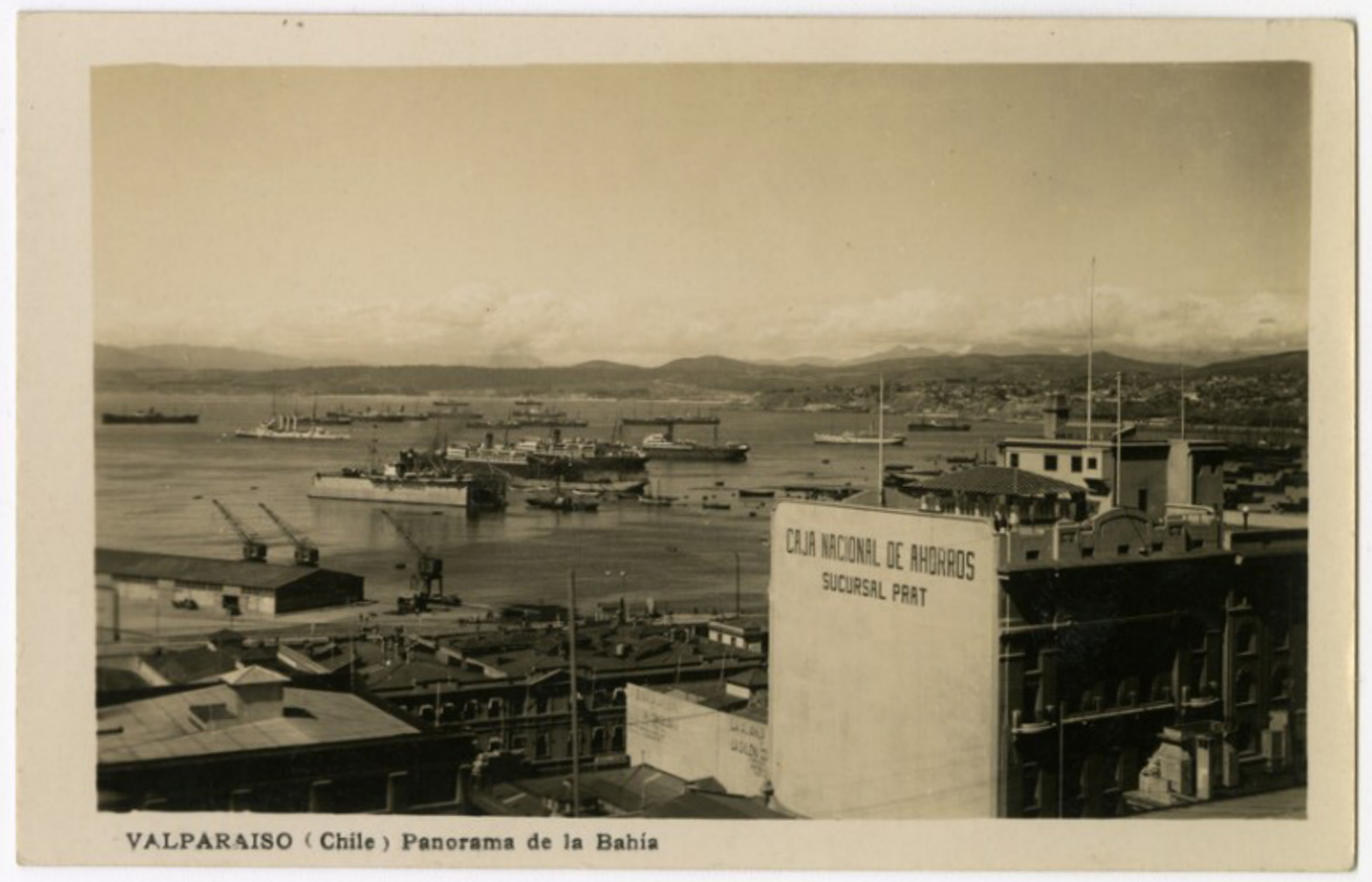

Valparaíso (Chile) Panorama de la Bahía: [Edificio de la Caja Nacional de Ahorros, Sucursal Prat] [fotografía]. Archivo Fotográfico. Disponible en Biblioteca Nacional Digital de Chile. Entre 1929 y 1939. http://www.bibliotecanacionaldigital.gob.cl/bnd/629/w3-article-612620.html . Accedido en 11/6/2020. 